\title{
What is the impact of the Covid-19 pandemic on the ENT surgical volume? A multicentric study in 3 university units
}

Rémi HERVOCHON ${ }^{1}$, sarah atallah ${ }^{2}$, sarah levivien ${ }^{3}$, pierre bonnefont ${ }^{1}$, Bertrand Baujat $^{4}$, Natacha Teissier ${ }^{5}$, and Frederic TANKERE ${ }^{6}$

${ }^{1}$ University Hospitals Pitié Salpêtrière-Charles Foix

${ }^{2}$ Assistance Publique - Hopitaux de Paris

${ }^{3}$ Robert-Debré Mother-Child University Hospital Division of Paediatric Medicine

${ }^{4}$ Hospital Tenon, Assistance Publique Hôpitaux Paris (APHP

${ }^{5}$ Hopital Universitaire Robert-Debre

${ }^{6}$ Hopitaux Universitaires Pitie Salpetriere-Charles Foix

May 18, 2020 What is the impact of the Covid-19 pandemic on the ENT surgical volume? A multicentric
study in 3 university units

Authors have no financial interest nor conflict of interest in the topic discusses in this paper

No financial support was obtained - No financial disclosure

Manuscript words count: 1250

FIVE KEY-POINTS

1. The 3 centers managed surgically 537 patients in 2019 , versus 87 in 2020 . This represents a global $84 \%$ decrease in terms of surgical volume.

2. The ratios calculated for other surgeries in other affected regions in the world are similar

3. The number of cervicotomies for cancer remained stable

4. The decreased volume is essentially at the expense of functional surgery

5. The number of scheduled tracheostomies increased from 8 to 22 .

\section{INTRODUCTION}

A novel coronavirus (severe acute respiratory syndrome coronavirus 2, SARS-CoV-2) causing a cluster of respiratory infections (coronavirus disease 2019, COVID-19) in Wuhan, China, was identified on January $7^{\text {th }}, 2020$. The epidemic quickly disseminated from Wuhan and, as at 12 February 2020, 45,179 cases were confirmed in 25 countries, including 1,116 deaths. Strengthened surveillance was implemented in France on January $10^{\text {th }}, 2020$ in order to identify imported cases early and prevent secondary transmission. Three cases of COVID-19 were confirmed on January $24^{\text {th }}$, the first cases in Europe (1). The 2 most affected French regions were Grand-Est and Paris Area. The confinement started in France on March $17^{\text {th }}$.

Following this announcement, the French Otorhinolaryngology - Head and Neck Surgery Society recommended to cancel all non-urgent medical or surgical activities, unless it would be expected to lead to a loss of chance for the patient. The purpose of this cancellation was to significantly increase critical care capacity; prioritize the reception of patients with Covid-19 and the allocation of staff and provision of the equipment necessary for their medical or surgical management; and contribute to the smooth running of downstream

critical care within their establishment. Another goal was to reduce the risks of patients contamination 
within healthcare facilities (2). This reorganization restricted access to the operating room, leading to fewer surgical procedures.

The aim of this study was to assess the impact of the Covid-19 pandemic on the surgical activity in three university ENT units located in Paris Area, a strongly affected region. This was performed by comparing activities accomplished during 1 month of pandemic to the same month in 2019.

\section{MATERIALS}

Local IRB was not solicited for this study because this retrospective observational study does not fall within the framework of the French law related to research involving humans (Loi n ${ }^{\circ} 2012-300$ du 5 mars 2012).

We studied two periods with 23 working days: from 17 March 2020 to 17 April 2020 and from 18 March 2019 to 18 April 2019. All patients operated on under general anesthesia during these two periods were included. There was no exclusion criterion. Data were collected in three university ENT units located in Paris Area. Center 1 (Pitié-Salpêtrière Hospital) is an adult general ENT unit, with an otological, otoneurosurgical, and facial palsy rehabilitation expertise. Center 2 (Tenon Hospital) is an adult general ENT unit, with an oncological expertise. The third center (Robert Debré Hospital) is a pediatric general ENT department.

We defined five groups of surgical procedures, according to anatomy: ear, nose, neck, face, and transoral surgeries. Sub-categories are presented in Table 1.

We also defined four groups of patients according to etiologies: cancer (except skin cancer), skin cancer, emergency and functional surgery.

A descriptive analysis of the decline of surgical volume in total and by type of surgical procedure was carried out between 2019 and 2020. All analyses and plots were conducted using the R software (v.3.6.0; 2020-04-26).

\section{RESULTS}

Six hundred and twenty-nine patients were included. Forty percent were female. There were 255 patients in center 1, 191 in center 2 , and 183 from center 3 .

In 2019, the daily average number of active operating rooms was 3.5 in center $1,2.4$ in center 2 , and 2.0 in center 3. In 2020, this was respectively $0.74,0.83$ and 0.22 . The global total number of surgeons was unchanged in 2020, except in center 2 (one fewer surgeon compared to 2019).

Five hundred and forty patients were operated on in 2019 versus 89 in 2020; this represents a global $84 \%$ decrease in terms of surgical volume, with respectively $88 \%$ in center $1,61 \%$ in center 2 , and $95 \%$ in the pediatric center. In respect to the type of surgery, otologic, endonasal, cervical, facial, and transoral surgeries activities decreased $97 \%, 91 \%, 54 \%, 82 \%$, and $85 \%$ respectively.

The characteristics of patients by type of surgery, etiology, sex, and center between 2019 and 2020 are presented in table 1.

The global number of cancer related procedures decreased (71 versus 44). This was mainly at the expense of skin cancers (24 versus 9), but the number of cervicotomies for cancer remained stable (18 versus 22 ).

The number of emergencies decreased by half (14 to 7) (figure 1).

The number of scheduled tracheostomies increased from 8 to 22 .

\section{DISCUSSION}

\section{Key findings}

In our three university ENT department, a global $84 \%$ decrease was noted in terms of surgical volume. This is mainly due to the strong reduction of functional surgery. We managed to keep neck surgery for cancer stable. 
Among the 6 ears operated on in 2020, 5 of them were stage IV vestibular schwannomas, thus corresponding to critical cases. We have found no explanation as to the global diminution of urgent surgeries, but the possible reduction of facial trauma due to confinement.

\section{Comparisons with other studies;}

In Seattle, USA, average weekly surgical volume decreased by $71.7 \%$ in a vascular surgery unit (3). In Milan, Italy, maxillo-facial units, outpatients surgery decreased by $86 \%$ and inpatients surgery decreased by $78 \%$ (4). In San Francisco, the department of surgery reduced operating room volume by $80 \%$ (5). In Marseille, France, during the first month of confinement, a decrease of almost $50 \%$ was observed in the number of spine surgical procedures (6).

However, the number of scheduled tracheostomies increased. Indeed, patients who become severely ill from COVID-19 have a high likelihood of needing prolonged intubation, making tracheostomy a likely consideration (7). In the context of the COVID-19 epidemic, the strategy adopted by many intensive care units consisted in early tracheostomy to wean off intubation in selective patients with severe ARDS and transfer them to a ventilatory weaning unit thus creating room for new patients in ICU $(8,9)$.

\section{Strengths and weaknesses of the study.}

To our knowledge, this is the first study comparing the ENT surgical volume between Covid-19 pandemic and a comparable period from the previous year. Our 3 different units are a good sample of the global ENT surgery activity in the Parisian region. Unfortunately, endonasal surgery only represented $10 \%$ of our overall activity in 2019, but the fact that only 5 endonasal procedures were performed in 2020 is enough to attest the strong decrease in terms of volume of this surgery.

In addition, this data can be very useful for the post-crisis management and if another crisis occurs later.

\section{Clinical applicability of the study.}

In total, $84 \%$ of scheduled surgical procedures were canceled and therefore will be rescheduled. A significant surplus of volume during the following months is therefore to be expected, requiring proper management. Also, we can anticipate that the postponement of these interventions may lead to spontaneous progression of the disease, and patients will probably present with more advanced disease stages or more complicated cases.

Thus, during a subsequent crisis, we should be able to select patients whose surgical intervention should be postponed at once, while maintaining significant surgical volume to avoid an excessive wave after the crisis.

In Paris Area, during April 2020, all the patients requiring ICU could be adequately treated. Paris Area hospitals were not overwhelmed, even if the government had at some stage to equip trains to transfer patients to other regions. It was thus feasible to maintain cancer related procedures. Most of the ENT cancer procedures can be performed without the need of a post-operative stay in ICU. The burden of this surgical activity on ICU beds is thus low in a context of pandemics. To minimize the loss of chance for the other patients should be a priority while facing a viral disease spread in the future.

\section{BIBLIOGRAPHY}

1. Bernard Stoecklin S, Rolland P, Silue Y, Mailles A, Campese C, Simondon A, et al. First cases of coronavirus disease 2019 (COVID-19) in France: surveillance, investigations and control measures, January 2020. Euro Surveill. 2020;25(6).

2. Couloigner V, Schmerber S, Nicollas R, Coste A, Barry B, Makeieff M, et al. COVID-19 and ENT Surgery. Eur Ann Otorhinolaryngol Head Neck Dis [Internet]. 2020 Apr 23 [cited 2020 May 8]; Available from: https://www.ncbi.nlm.nih.gov/pmc/articles/PMC7177055/

3. Hemingway JF, Singh N, Starnes BW. Emerging Practice Patterns in Vascular Surgery During the 
COVID-19 Pandemic. J Vasc Surg [Internet]. 2020 Apr 30 [cited 2020 May 8]; Available from: https://www.ncbi.nlm.nih.gov/pmc/articles/PMC7190553/

4. Allevi F, Dionisio A, Baciliero U, Balercia P, Beltramini GA, Bertossi D, et al. Impact of COVID-19 epidemic on Maxillofacial Surgery in Italy. Br J Oral Maxillofac Surg [Internet]. 2020 May 3 [cited 2020 May 8]; Available from: https://www.ncbi.nlm.nih.gov/pmc/articles/PMC7196423/

5. Lancaster EM, Sosa JA, Sammann A, Pierce L, Shen W, Conte MC, et al. Rapid Response of an Academic Surgical Department to the COVID-19 Pandemic: Implications for Patients, Surgeons, and the Community. J Am Coll Surg [Internet]. 2020 Apr 9 [cited 2020 May 8]; Available from: https://www.ncbi.nlm.nih.gov/pmc/articles/PMC7194622/

6. Meyer M, Prost S, Farah K, Denis J-B, Dufour H, Blondel B, et al. Spine Surgical Procedures during Coronavirus Disease 2019 Pandemic: Is It Still Possible to Take Care of Patients? Results of an Observational Study in the First Month of Confinement. Asian Spine J. 2020 May 8;

7. Mecham JC, Thomas OJ, Pirgousis P, Janus JR. Utility of Tracheostomy in Patients with COVID-19 and Other Special Considerations. Laryngoscope. 2020 May 5;

8. Schultz P, Morvan J-B, Fakhry N, Morinière S, Vergez S, Lacroix C, et al. French consensus regarding precautions during tracheostomy and post-tracheostomy care in the context of COVID-19 pandemic. Eur Ann Otorhinolaryngol Head Neck Dis [Internet]. 2020 Apr 9 [cited 2020 May 8]; Available from: https://www.ncbi.nlm.nih.gov/pmc/articles/PMC7144608/

9. Michetti CP, Burlew CC, Bulger EM, Davis KA, Spain DA. Performing tracheostomy during the Covid-19 pandemic: guidance and recommendations from the Critical Care and Acute Care Surgery Committees of the American Association for the Surgery of Trauma. Trauma Surg Acute Care Open [Internet]. 2020 Apr 15 [cited 2020 May 8];5(1). Available from: https://www.ncbi.nlm.nih.gov/pmc/articles/PMC7186881/

\section{Hosted file}

Figure1.docx available at https://authorea.com/users/310073/articles/451714-what-is-theimpact-of-the-covid-19-pandemic-on-the-ent-surgical-volume-a-multicentric-study-in-3university-units

\section{Hosted file}

Table1 complet.docx available at https://authorea.com/users/310073/articles/451714-what-isthe-impact-of-the-covid-19-pandemic-on-the-ent-surgical-volume-a-multicentric-study-in3-university-units 